\title{
Long-time survival of a female with primary amyloidosis treated by peritoneal dialysis
}

\author{
Agnieszka M Grzebalska', Jarosław Sak ${ }^{1,2}$, Andrzej Prystupa ${ }^{3}$, Andrzej Książek' \\ ${ }^{1}$ Department of Nephrology, Medical University of Lublin, Lublin, Poland \\ ${ }^{2}$ Department of Ethics and Human Philosophy, Medical University of Lublin, Lublin, Poland \\ ${ }^{3}$ Department of Internal Medicine, Medical University of Lublin, Lublin, Poland
}

Grzebalska A M, Sak J, Prystupa A, Książek A. Long-time survival of a female with primary amyloidosis treated by peritoneal dialysis. J PreClin Clin Res. 2017; 11(1): 22-24. doi: 10.26444/jpccr/75444

\begin{abstract}
Introduction. Amyloidosis, both primary and secondary, is a systemic disease characterized by extracellular deposition of fibrillar protein in vital organs, leading to their injury and even insufficiency. It results in a poor diagnosis, especially for patients with primary amyloidosis. Kidney involvement is typical and usually manifests by proteinuria, mainly nephrotic range, leading to end-stage renal disease (ESRD). Patients with ESRD need renal replacement therapy (RRT). Some data claim that better results and longer patient' survival are observed in peritoneal dialysed rather than in haemodialysed patients. Case report. The case is described of 19-year-old Caucasian woman with primary amyloidosis. Inherited primary amyloidosis with abnormal apolipoprotein A-I was established. The patient was successfully treated with peritoneal dialysis for 87 months. After this period, she was transferred for haemodialysis. Such a long survival time on peritoneal dialysis (PD) in a patient with primary amyloidosis has not been found. It is believed that the lowering of immunoglobulin levels in blood and normalization of total protein in serum effectively removed, through dialysate, the pathological polyclonal proteins. This effect probably also sustained cardio-circulatory sufficiency of the patient and significantly prolonged her survival. Conclusion. Peritoneal dialysis is an effective and recommended method of treatment in patients suffering from primary amyloidosis. Peritoneal dialysis should be the first choice therapy in ESRD patient; contrary to haemodialysis, peritoneal dialysis removes pathological proteins and allows the avoidance of intra-dialytic hypotension.
\end{abstract}

\section{Key words}

Amyloidosis, kidney failure, peritoneal dialysis, end-stage renal disease

\section{INTRODUCTION}

Amyloidosis is a systemic disease characterized by homogenous protein fibrils depositions present in many organs and leading to their injury. The prognosis is rather poor - the median survival is usually less than 18 months [1]. In both types of amyloidosis, primary and secondary, kidney involvement is typical and frequent $[2,3,4]$. It usually manifests by proteinuria, mainly of nephrotic range $[2,5]$. The standard treatment of amyloidosis, e.g. using kolchicyne, melphalan with prednisone or cyclophosphamide with prednisone, can extend the median survival of patients [1]. Nowadays, the most effective treatment is a high-dose of melphalan followed by autologous stem cell transplantation. Further renal transplant has even been postulated [4]. Amyloid deposition, prolonged proteinuria and performed treatment of amyloidosis can injury the kidney, and finally lead to endstage renal disease (ESRD) [2, 4]. If ESRD occurs, patients can be treated with all standard types of renal replacement therapy (RRT): peritoneal dialysis (PD), haemodialysis (HD) or renal transplant. Some authors suggest that better patients survival in PD than in HD [6]. In most available reports, amyloidosis patients on $\mathrm{PD}$ the survival rate was satisfactory but not impressive $[2,3,7]$. The case is presented of a woman with primary amyloidosis successfully treated with PD for more than seven years ( 87 months).

Address for correspondence: Jarosław Sak, Department of Ethics and Human Philosophy, Medical University of Lublin, ul. Staszica 4/6, 20-059 Lublin

E-mail: jareksak@tlen.pl

Received: 9 March 2016; accepted: 24 April 2017

\section{CASE REPORT}

In May 1995, a 19-year-old Caucasian woman was hospitalized because of generalizated oedema and proteinuria, nephrotic range (up to $10.0 \mathrm{~g} /$ day) (Tab. 1). Normal blood pressure was observed $(120 / 70 \mathrm{mmHg})$, normal renal function (urea$24 \mathrm{mg} \%$, creatinin $0,7 \mathrm{mg} \%)$, hipoproteinaemia $(4,6 \mathrm{~g} / \mathrm{L})$, albuminemia $(30,6 \%)$ and hiper- $\gamma$-globulinemi $(21,4 \%)$.

Immunoglobulins were moderate elevated: IgG-1500 mg/dl (n. 850-1350 mg/dl), IgA-460 mg/dl (n.160-330 mg/dl), IgM-500 mg/dl (n.95-165 mg/dl). Secondary reasons of nephrotic syndrome (chronic inflammatory process, neoplasms) were excluded, and renal biopsy performed, which failed. No biopsy of rectal or oral tunica mucosa was performed. The patient was given intravenously 3 pulses of methylprednisolone of $1 \mathrm{~g}$ each, followed by prednisone (40 mg/day). A decrease in proteinuria was achieved. In May 1998, because of a sudden decrease in renal function (creatinin $1.7 \mathrm{mg} \%$ ), another renal biopsy was performed and found typical features of amyloidosis: positive Congo red stain deposits of amyloid in glomerulus, blood vessels walls, interstitium and even in the basement membrane of tubules (Tab. 1). Inherited primary amyloidosis with abnormal apolipoprotein A-I was established. From then on, the patient was treated with $0.5 \mathrm{mg} /$ day colchicines, administered orally. Pulses of cyclophosphamide $400 \mathrm{mg} / \mathrm{month}$ i.v. were given. Creatinin level established at 2.1-3.1 mg\%, but nephritic range proteinuria was still (up to $7 \mathrm{~g} /$ day). Low levels of total protein $-4.8 \mathrm{mg} / \mathrm{dl}$ and albumin $1.6 \mathrm{mg} / \mathrm{dl}$ were found, together with high levels of all types of immunoglobulin; IgG-2300 mg/dl was especially high (n. 850-1350 mg/dl). 
Table 1. Disease history of primary amyloidosis 1995-2007

\begin{tabular}{|c|c|c|c|c|}
\hline & May 1995 & May 1998 & October 1999 & January 2007 \\
\hline Age & 19 & 22 & 23 & 30 \\
\hline Blood pressure & $120 / 70$ & & $130 / 100,145 / 105$ & \\
\hline Proteinuria & up to $10,0 \mathrm{~g} /$ day & up to $7 \mathrm{~g} /$ day & & \\
\hline Renal function & Normal & Dysfunction & End-stage renal dysfunction & End-stage renal dysfunction \\
\hline Creatinin level & $0.7 \mathrm{mg} \%$ & $1.7 \mathrm{mg} \%$ & & \\
\hline IgG level (normal range: $850-1350 \mathrm{mg} / \mathrm{dl}$ ) & $1500 \mathrm{mg} / \mathrm{dl}$ & $2300 \mathrm{mg} / \mathrm{dl}$ & $1755 \mathrm{mg} / \mathrm{dl}$ & \\
\hline IgA level (normal range: $160-330$ mg/dl) & $460 \mathrm{mg} / \mathrm{dl}$ & & $615 \mathrm{mg} / \mathrm{dl}$ & \\
\hline IgM level(normal range: 95-165 mg/dl) & $500 \mathrm{mg} / \mathrm{dl}$ & & $207 \mathrm{mg} / \mathrm{dl}$ & \\
\hline Total protein level & $4.6 \mathrm{~g} / \mathrm{L}$ & $4.8 \mathrm{~g} / \mathrm{L}$ & $7.9 \mathrm{~g} / \mathrm{L}$ & \\
\hline Renal biopsy & failed & typical features of amyloidosis & & \\
\hline Treatment & $\begin{array}{l}\quad 3 \text { pulses of } \\
\text { methylprednisolone }(3 \times 1 \mathrm{~g})\end{array}$ & $\begin{array}{l}\text { pulses of cyclophosphamide } \\
0,4 \mathrm{~g} / \text { month }\end{array}$ & Peritoneal dialysis (started) & Haemodialysis (started) \\
\hline
\end{tabular}

Huge anaemia (Hgb 7.6g/l) necessitated the performance of marrow biopsy, in which amyloid deposits were found. The treatment was changed to orally administered melphalan $(6 \mathrm{mg} / 24 \mathrm{~h})$ and prednisone $(0.8 \mathrm{mg} / \mathrm{kg})$ for 7 days every month. This treatment was performed from April 2000-2001. The same schema was then given every 2 months until April 2002.

In October 1999, because of ESRD, a Tenckhoff catheter was inserted into the patient's peritoneal cavity and PD treatment started. Initially, continuous ambulatory peritoneal dialysis (CAPD) was performed, but because of dialysate lack into the abdominal wall this was changed to automatic peritoneal dialysis (APD). Despite supplementation of epoietin and iron, secondary anaemia (Hgb level $8.7 \mathrm{~g} / \mathrm{l}$ ) was observed. In the subsequent marrow biopsy, progressive marrow injury was observed. In order to improve marrow function, the patient was given prednisone $20 \mathrm{mg}$ /day. Total protein level was $7.9 \mathrm{~g} / \mathrm{l}$; albumin $3,38 \mathrm{~g} / \mathrm{l}$. Immunoglobulin levels reduced to the values: $\operatorname{IgG}-1755 \mathrm{mg} / \mathrm{dl}(\mathrm{n} .700-1600 \mathrm{mg} / \mathrm{dl})$, IgA-615 mg/dl (n.70-400 mg/dl), and IgM-207 mg/dl (20$230 \mathrm{mg} / \mathrm{dl}$ ), respectively. Improvement was observed in peripheral blood (Hgb 10.9g/l) and general clinical status of the patient.

At the beginning of the disease the patient revealed normal values of blood pressure $(120 / 70 \mathrm{mmHg})$, and when PD was started, blood pressure was 130/100 to145/105 mmHg. In January 2007, because of a massive peritonitis, peritoneal dialysis was stopped. After 87 months of peritoneal dialysis treatment the patient was transferred to haemodialysis.

\section{DISCUSSION}

Systemic amyloidosis results in extracellular deposition of fibrillar protein in vital organs, leading to their injury and even finally insufficiency. It results in a poor diagnosis, especially for patients with primary amyloidosis $(\mathrm{AL})[3,8,9]$.

Renal involvement is frequent in both types of amyloidosis, and can affect up to $75 \%$ of cases.[3]. Long-time survival is rather rare. Esteve et al. found that survival time in $\mathrm{AL}$ patients was shorter than in those with secondary amyloidosis (AA): $58 \%$ and $19 \%$ at 12 and 24 month vs $55 \%$ and $44 \%$, respectively [3]. Bollée et al. also observed that median survival in AL dialyzed patients was only 26 months [9]. A long-term survival of patients with primary amyloidosis was described by Kyle et al., who observed 10 years or more survival in $4.7 \%$ of 810 patients with AL [10]. Kumar et al., when examined the trends in overall survival in patients with primary amyloidosis, during the period 1977-2006 found significant improvement in survival time [11]. There is no doubt, that one of factors improving survival in amyloidosis is better and earlier treatment.

Standard treatment for primary amyloidosis consists of orally given melphalan with prednisone [8]. In the presented case, after the first failed renal biopsy, the patient was treated by being given pulses of methylprednisolone, followed by oral prednisone. When the next renal biopsy was performed in the then 23-year-old patient and the diagnosis of primary amyloidosis established, she was given colchicine orally $(0.5 \mathrm{mg} /$ day $)$, and cyclophosphamide intravenously as a pulse (400 mg) every month. Deterioration in renal function was the reason for starting PD. Because of significant anaemia, marrow biopsy was performed, which found amyloid deposits. Orally given melphalan with prednisone was introduced. As described by Gertz at al., the median time from diagnosis to starting dialysis was 13.8 months [12]. The patient started peritoneal dialysis 53 months after proteinuria occurred, and 17 months after amyloidosis was confirmed in renal biopsy.

A newly- established method of AL treatment is using a high-dose of melphalan given intravenously, followed by autologous stem cell transplantation $[4,8]$. A crucial question in such patients remains: when and whether to perform renal transplant? [4]. Furthermore, this type of treatment can be offered only to patients with a good general status and with limited cardiac involvement [8]. Unfortunately, the patient in the presented case was disqualified from renal transplant.

Kidney involvement in amyloidosis, as described above, usually leads to ESRD, which needs RRT. It is a matter of interest, which method of RRT is better for the patients: haemodialysis or peritoneal dialysis? Already in the late 1970s, Stone et al. used PD to treat patients with amyloidosis who needed RRT. They demonstrated that paraproteins were removed in dialysate [13]. The improvement in electrophoresis of serum proteins and decrease in immunoglobulin serum levels was also noticed in the presented case. On the other hand, Moroni et al. found no differences in survival rates between patients treated with HD versus those treated with $\mathrm{PD}$, although patients younger than 45 years had a longer survival time [14]. The same authors found an intra-dialytic hypotension as the most common complication of HD, 
while in PD patients the most common complication was peritonitis. [14]. This is consistent with the observation in the current case: the female lost the possibility to be treated by PD because of peritonitis. Esteve et al. found that mean the survival time of 12 and 24 months after the start of dialysis was $30 \%$ and $5 \%$, respectively [9]. Gude et al. have also described a case of short-time PD treatment in primary amyloidosis [7]. The female patient in the current case survived on peritoneal dialysis for 87 months in a general quite well state. No other such long survival time on PD in a patient with primary amyloidosis has been found. It is believed that the lowering of immunoglobulin levels in blood and normalization of total protein in serum resulted in the removal, with dialysate, of pathological polyclonal proteins. This effect also probably sustained cardio-circulatory sufficiency of the patient and significantly prolonged her survival.

\section{CONCLUSION}

According to the results obtained, peritoneal dialysis is an effective and recommended method of treatment in patients suffering from primary amyloidosis. Peritoneal dialysis should be the first choice therapy in ESRD patients; contrary to haemodialysis, peritoneal dialysis removes pathological proteins and allows the avoidance of intra-dialytic hypotension. Moreover, peritoneal dialysis is a safe method which markedly prolongs the patient's survival, mainly in those with no possibility to undergo renal transplantation.

\section{REFERENCES}

1. Kyle RA, Gertz MA, Greipp PR, Witzig TE, Lust JA, Lacy MQ, Therneau TM. A trial of three regiments for primary amyloidosis: colchicine alone, melphalan and prednisone, and melphalan, prednisone, and colchicyne. N Engl J Med. 1997; 336: 1202-1207.
2. Browning MJ, Banks RA, Harrison P, Tribe CR, Fraley CT, Zachary G, Mackenzie C. Continuous ambulatory peritoneal dialysis in systemic amyloidosis and end-stage renal disease. J R Soc Med. 1984; 77: 189-192. 3. Esteve V, Almirall J, Ponz E, García N, Ribera L, Larrosa M, Andreu $\mathrm{X}$, García M. Renal involvement in amyloidosis. Clinical outcomes, evolution and survival. Nefrologia 2006; 26: 212-217.

4. Merlini G, Remuzzi G. Autologous stem cell and kidney transplantation for primary amyloidosis associated with ESRD: Which should come first? Am J Transplant. 2005; 5: 1585-1586.

5. Ronco P, Aucouturier P, Mougenot B. Plasma cell dyscrasia-related glomerulopathies and Fanconi's syndrome: a molecular approach. J Nephrol. 2000; 13(suppl 3): S34-S44.

6. Tielemans C, Dratwa M, Bergmann P, Goldman M, Flamion B, Collart F, Wens R. Continuous ambulatory peritoneal dialysis vs hemodialysis: A lesser risk of amyloidosis? Nephrol Dial Transplant. 1988; 3: 291-294.

7. Gude D, Chennemsetty S, Jha R, Narayan G. Primary amyloidosis treatment with continuous ambulatory peritoneal dialysis. Letter to Editor. Saudi J Kidney Dis Transplant. 2012; 23: 1285-1287.

8. Sanchorawala V, Wright DG, Seldin DC, Dember LM, Finn K, Falk RH, Berk J, Quillen K, Skinner M. An overview of the use of high-dose melphalan with autologous stem cell transplantation for the treatment of AL amyloidosis. Bone Marrow Transplant. 2001; 28: 637-642.

9. Bollée G, Guery B, Joly D, Snanoudj R, Terrier B, Allouache M, Mercadal L, Peraldi MN, Viron B, Fumeron C, Elie C, Fakhouri F. Presentation and Outcome of patients with systemic amyloidosis undergoing dialysis. Clin J Am Soc Nephrol. 2008; 3: 375-381.

10. Kyle RA, Gertz MA, Greipp PR, Witzig TE, Lust JA, Lacy MQ, Therneau TM. Long-term survival (10 years or more) in 30 patients with primary amyloidosis. Blood, 1999; 93: 1062-1066.

11. Kumar SK, Gertz MA, Lacy MQ, Dingli D, Hayman SR, Buadi FK. Recent improvements in survival in primary systemic amyloidosis and the importance of an early mortality risk score. Mayo Clin Proc. 2011; 86: 12-18.

12. Gertz MA, Kyle RA, O'Falkon WM. Dialysis support of patients with primary systemic amyloidosis. A study of 211 patients. Arch Intern Med. 1992; 152: 2245-2250.

13. Stone WJ, Latos DL, Lankford PG, Baker AS. Chronic peritoneal dialysis in a patient with primary amyloidosis, renal failure, and factor X deficiency. South Med J. 1978; 71: 764-767.

14. Moroni G, Banfi G, Montoli A, Bucci A, Bertani T, Ravelli M, Pozzi C, Leonelli M, Lupo A, Volpi A. Chronic dialysis in patients with systemic amyloidosis: the experience in northern Italy. Clin Nephrol. 1992; 38: 81-85. 